\title{
Penetrating Injuries to the Spleen and Kidney: an Evolution in Progress
}

\author{
Bellal Joseph $^{1} \cdot$ Mazhar Khalil $^{1} \cdot$ Peter Rhee $^{1}$
}

Published online: 14 April 2015

(C) Springer International Publishing AG 2015

\begin{abstract}
Optimal management of penetrating abdominal trauma, especially for kidney and splenic injuries, is evolving. Opinions range from aggressive surgical exploration to expectant management. This report addresses the recent advancements in the diagnosis, grading, and management of penetrating injuries to the kidney and spleen. A special focus is provided on the shifting paradigm towards non-operative management. Penetrating renal trauma management has evolved significantly over the past few years. Advancements in diagnostic tools and evolution of injury grading have paved the way for selective non-operative management. Penetrating injuries to the spleen provide a unique management challenge. With the evolution of non-operative management, appropriate patient selection is mandatory. Optimal use of computed tomography scanning and angiography can improve the organ salvage rates; however, hemorrhage control is still the main goal.
\end{abstract}

Keywords Penetrating renal injuries $\cdot$ Penetrating splenic injuries $\cdot$ Penetrating abdominal trauma $\cdot$ Operative management $\cdot$ Non-operative management $\cdot$ Review

\section{Introduction}

Controversy still exists regarding the optimal management of penetrating abdominal trauma. Opinions range from aggressive surgical exploration to expectant management whenever possible [1]. Until recently, exploratory laparotomy was considered

This article is part of the Topical Collection on Penetrating Injuries to Solid Abdominal Viscera

Bellal Joseph

bjoseph@surgery.arizona.edu

1 Division of Trauma, Emergency Surgery, Critical Care, and Burns, Department of Surgery, University of Arizona, 1501 N. Campbell Ave, Room 5411, P.O. Box 245063, Tucson, AZ 85724, USA the gold standard for the management of penetrating abdominal trauma, but this can result in a 27 to $53 \%$ negative laparotomy rate $[2,3]$. This high rate of negative exploration and the morbidity of this procedure provided the impetus towards a more selective approach in the management of penetrating abdominal trauma. Selecting the ideal candidate for non-operative management remains challenging [1].

Recent advancements in diagnostic tools have furthered the interest in non-operative management of penetrating abdominal trauma $[4,5]$. It has been demonstrated that there are select groups of patients with solid organ injuries that can frequently be managed without mandatory laparotomy $[6 \bullet, 7]$. The utility of non-operative management in penetrating abdominal trauma has been extended to the management of renal and splenic penetrating trauma [8].

Renal injury is the most frequently encountered urologic injury but most are due to blunt trauma [9]. While the utility and efficacy of operative intervention is evolving, the nonoperative management in renal trauma is also making its way [10]. Although the presence of hemodynamic instability, peritonitis, evisceration, or any other evidence of peritoneal violation mandates laparotomy, the presence of minor renal injuries can be managed non-operatively. In the case of hemodynamically stable penetrating trauma patients with suspicion of renal injury, a thorough workup can help decide the need for operative intervention.

The spleen on the other hand is one of the most frequently injured abdominal solid organs in blunt trauma, with a penetrating injury, due to the relatively small size of the spleen, rate less than other organs such as the liver or hollow viscous. For minor penetrating splenic injury identified during laparotomy, repair and drainage or just drainage alone is an option if the patient is hemodynamically stable or there is no further bleeding. For isolated splenic injury, non-operative management is also an option. The literature for non-operative management is encouraging, however, insufficient to make any strong recommendations at current stage. 
This report addresses the recent advances in diagnosis and management of injuries of two important solid organs: the kidney and the spleen. A special focus is provided on the shifting paradigm towards non-operative management.

\section{Penetrating Renal Trauma}

Renal injury is the most frequently encountered urologic injury after trauma [7]. Although a vast majority of renal injuries result from blunt abdominal trauma, penetrating trauma does account for a significant number of renal injuries [11]. Most often the renal injuries are minor and do not require further workup. However, the rate of significant renal injury is much higher in penetrating renal trauma compared to blunt trauma. Often the penetrating injury to the kidney is complicated with the associated abdominal injuries. Kansas et al., in their study on penetrating renal injuries from an urban setting, reported that around $95 \%$ of the patients had associated abdominal injuries with majority of them being solid organ injuries [11]. Also the location and mechanism of penetrating injury may affect the injury pattern and hence the management plan. Armenakas et al., in their study on stab wounds (SW) to the kidney, found a weak correlation between the stabbing site and grade of renal injury. They found that SW to the flank was more likely to have higher renal injury grade compared to anterior abdominal, back, and thoracoabdominal wounds [12].

In hemodynamically stable patients where staging of the renal injury can be done, nephron sparing surgery or nonoperative intervention can significantly improve renal salvage rates [13]. While renal salvage after operative repair has seen significant improvement over the years, selective nonoperative management of mild to moderate injuries has proven itself as safe and beneficial.

Diagnosis The diagnosis of renal trauma relies on a combination of clinical examination, laboratory findings, and radiographic imaging. The absence of hemodynamic instability, peritonitis, and evisceration or evidence of loss of fascial integrity is a criterion for non-operative candidates, and further diagnostic evaluation can determine if surgery is required or not.

a) Physical exam: An important indicator of renal injury in penetrating trauma is location and trajectory of the bullet or knife. A high index of suspicion for renal injury must be maintained in all penetrating injuries to the abdomen, thoracoabdomen, and back. Presence of gross hematuria in the setting of penetrating abdominal wounds demands high suspicion for renal trauma and is associated with high-grade renal injuries.

b) Urinalysis: One of the important initial investigations following renal trauma is urinalysis. Presence of either gross or microscopic hematuria in the setting of a penetrating mechanism is associated with severe renal injuries. However, in contrast to blunt trauma, in penetrating trauma, the absence of hematuria does not exclude the diagnosis of renal trauma $[14,15]$. Wilson et al., in their retrospective review of 101 patients with penetrating renal trauma, found that $12 \%$ did not have hematuria, and of the patients with injuries to renal pelvis, $45 \%$ had normal urinalysis [16]. Hematuria in the presence of hemodynamic instability predicts severity of injury; however, its absence should not rule out renal injury [17]. In summary, although useful, routine use of urinalysis in penetrating trauma does not seem to be of any significant benefit.

c) Sonography: Similar to urinalysis, ultrasound (US) demonstrating injury affirms renal injury as it is specific; however, the absence of findings on ultrasound does not preclude renal injury as US is not sensitive. McGahan et al., in a prospective study of 20 patients, reported that US was able to detect renal parenchymal injury in only $22 \%$ of the patients [18]. The utility of US is minimal, if any, in the initial evaluation of penetrating renal trauma. The limitations stem from the difficulty in obtaining good acoustic windows on the trauma patient who has sustained numerous associated injuries. The results are highly dependent on the operator. Even when US do identify renal lacerations, it cannot definitely assess their depth and extent. In addition, they do not provide information on renal function. Thus the US is recommended in the evaluation of the penetrating trauma patient since it is readily available, quick, and non-invasive; however, the information provided is limited.

d) Intravenous pyelography: Intravenous pyelography (IVP) traditionally has been the imaging of choice in hemodynamically stable patients with suspected renal injury. In the hemodynamically unstable patients with indications for laparotomy, the one-shot IVP was recommended to determine the presence of two functioning kidneys. However, with the advent of computed tomography (CT) scan and literature reporting the higher sensitivity and specificity of CT scans for diagnosing renal injuries, its utility has gone down significantly [19].

The value of on table one-shot IVP in unstable patients undergoing laparotomy has also been questioned. The proponents for this study state that the rationale is that the study is safe, efficient, and of high quality in the majority of cases [20]. It provides important information for decision-making in the critical time of urgent laparotomy, concerning the injured kidney, as well as the presence of a normal functioning kidney on the contralateral side [10]. However, those that argue against its use state that the study is time consuming and difficult to obtain with good quality and that the intraoperative manual palpation of the uninjured kidney is sufficient in case the injured kidney requires surgical removal. The argument is that although 
agenesis of the kidney is rare but possible, the chances of the contralateral uninjured kidney being non-functional if the kidney is normal in size are extremely small.

e) Computed tomography scan: CT scan is the preferred imaging modality for diagnosing renal injuries and is the study of choice. Along with added advantage of providing anatomic and special information as well as functionality, $\mathrm{CT}$ is more sensitive and specific than conventional diagnostic tools such as IVP $[19,21]$. Halsell and Cass et al., in prospective comparisons between CT scan and IVP, found that $\mathrm{CT}$ scan to be more sensitive and specific in detecting renal injuries [22, 23].

CT is the current gold standard method for the radiographic assessment of stable patients with renal trauma. The major disadvantage of CT scan is its higher cost, but $\mathrm{CT}$ is more sensitive and specific than conventional diagnostic tools such as IVP, ultrasonography, or angiography. Qin et al., in a retrospective study, found that CT detected $95.6 \%$ of injuries, double-dose IVP detected $90.9 \%$, and ultrasound detected $78.8 \%$ injuries [21].

CT accurately defines the injury location, visualizes the entire retroperitoneum, and provides a view of the abdomen and pelvis as well. It demonstrates superior anatomical detail, including the depth and location of renal laceration and presence of associated abdominal injuries, and establishes the presence and location of the contralateral kidney.

f) Magnetic resonance imaging: MRI is becoming more and more sophisticated over time. Most of the studies looking at the utility of MRI in renal trauma found it more sensitive to CT scan for certain kind of injuries [24, 25]. Leppaniemi et al., in their study, reported MRI to be highly sensitive for retroperitoneal hematoma, viability of renal segments, and preexisting renal disease; however, MRI was not sensitive for detecting urinary extravasation [26]. Ku et al. in their study comparing the CT and MRI reported clear superiority of MRI for detecting renal pelvic fracture over CT scan [25].

The utility of MRI is limited secondary to its availability, longer study duration, and higher cost. The only role of MRI after renal trauma can be defined for patients with contrast allergies or in stable patients with equivocal findings on $\mathrm{CT}$ scan.

Renal Injury Grading The American Association for the Surgery of Trauma (AAST) has published a renal injury grading scale based on the anatomic injury identified on CT scan (Table 1 [27]). The grade of injury correlates with the anatomic deficits and dictates the management of renal injury [28].

Management When managing patients with renal injuries, the goal is to minimize morbidity and preserve renal function.
Renal exploration thus should be undertaken selectively. The management of renal injury usually depends on the decision to explore or observe based on associated abdominal injuries. Indications for operative exploration include hemodynamic instability due to renal hemorrhage or an expanding or pulsatile peri-renal hematoma identified at exploratory laparotomy for associated injuries $[12,29]$. Renal exploration can be spared if preoperative or intraoperative radiographic studies reveal an injury that can be observed safely. Although not routine, a one-time, intraoperative IVP may be of some use in such a situation [20]. Poor visualization or other abnormalities of the injured kidney on IVP are indications for exploration. By definition, grade $\mathrm{V}$ renal injuries absolutely indicate exploration. Renal vascular injuries showing no flow to the kidney may also indicate surgery.

For a few decades, there has been controversy about the management of major renal injuries with urinary extravasation and devitalized fragments. Because these injuries are very uncommon, the published data report on small numbers of patients. Thall et al., in their study, reported successful expectant management in patients with grade III renal injuries [30]. Similarly, Demetriades et al. found expectant management to be reasonable in high-grade renal injuries [7].

a) Operative management: The initial primary goal of renal exploration after penetrating renal trauma is renal salvage. Renal reconstruction is possible in most cases. The overall rate of patients who have a nephrectomy during exploration is about $13 \%$. With gunshot injuries caused by a high-velocity bullet, reconstruction is very difficult, and usually a nephrectomy will be required.

Reno vascular injuries are uncommon and often associated with extensive associated trauma and increased peri- and post-operative mortality and morbidity. An attempt to repair is justified in cases where the patient has only a solitary kidney or has sustained bilateral injuries. In all other cases, nephrectomy is likely the treatment of choice. In rare situations when a patient has an unsalvageable vascular injury to the kidney and does not have a functional kidney on the other side, some have suggested that the functional kidney that has been removed be flushed with cold saline and preserved in ice for potential replantation. However, even in the best of circumstances, the time from injury to nephrectomy is not short enough and warm ischemia has ensued, making the kidney unsalvageable.

Some of the factors that influence the extent of operative repair include the hemodynamic status of the patient, location of the injury, extent of tissue damage, presence or absence of other kidney, and renovascular injuries. If tissue damage is limited to either pole of the kidney, a partial nephrectomy can be performed. Partial nephrectomy requires extensive debridement of non-viable tissue down 
Table 1 Modified AAST renal injury grading

\begin{tabular}{|c|c|c|}
\hline Grade & Type of injury & Description \\
\hline \multirow[t]{2}{*}{ I } & Parenchyma & Sub-capsular hematoma and/or contusion \\
\hline & Collecting system & No injury \\
\hline \multirow[t]{2}{*}{ II } & Parenchyma & $\begin{array}{l}\text { Laceration }<1 \mathrm{~cm} \text { cortical depth, small hematoma contained } \\
\text { within Gerota's fascia }\end{array}$ \\
\hline & Collecting system & No injury \\
\hline \multirow[t]{2}{*}{ III } & Parenchyma & $\begin{array}{l}\text { Laceration }>1 \mathrm{~cm} \text { cortex depth and into the medulla, hematoma } \\
\text { contained within Gerota's fascia }\end{array}$ \\
\hline & Collecting system & No injury \\
\hline \multirow[t]{2}{*}{ IV } & Parenchyma & $\begin{array}{l}\text { Parenchymal laceration into collecting system or vascular injury } \\
\text { to segmental vein or artery }\end{array}$ \\
\hline & Collecting system & $\begin{array}{l}\geq \text { laceration into collecting system with urinary extravasation or renal } \\
\text { pelvis laceration with or without complete uretral pelvic disruption }\end{array}$ \\
\hline V & Vascular & $\begin{array}{l}\text { Laceration or avulsion of main renal artery or vein or thrombosis of } \\
\text { main renal artery or vein }\end{array}$ \\
\hline
\end{tabular}

to the active bleeding. Individual vessels can be suture ligated using absorbable sutures and parenchymal bleeding can be controlled by direct pressure. Once the hemostasis is achieved, collecting system should be repaired using a running watertight suture. A leak test can be performed using methylene blue injection into renal pelvis and compressing the ureter while inspecting for extravasation. The defect is closed by pulling the capsule together or if sufficient capsule is unavailable, an omental flap can be used.

If the injury involves the middle portion of the kidney, operative approach is renorrhaphy. Following debridement and hemostasis, the parenchymal edges are approximated and anchored to the capsule using absorbable sutures over gelatin bolster. A retroperitoneal drain without suction should be placed after partial nephrectomy and renorrhaphy.

In case of hemodynamic instability, renovascular avulsion or grade $\mathrm{V}$ renal injury nephrectomy becomes inevitable. For nephrectomy, renal artery is ligated followed by renal vein. The ureter should be ligated close to the bladder.

b) Non-operative management: All grade I and II penetrating renal injuries can be managed non-operatively. Therapy of grade III injuries has been controversial for many years. Improved results in all recent studies support expectant treatment [12, 30-32]. The majority of patients with grade IV and V renal injuries present with major associated injuries, with resultant high exploration and nephrectomy rates. Demetriades et al., in their study on penetrating abdominal trauma, reported successful expectant management of even the higher-grade renal injuries in majority of the patients [7].

Renal gunshot injuries involving the hilum are almost always explored even if not bleeding as they are accompanied by hollow viscous injury. It is difficult to injure the renal hilum with tangential wounds as these circumstances are rare. Low-velocity gunshot and stab wounds to the periphery of the kidney resulting in minor injury may be managed conservatively with an acceptably good outcome. Meanwhile, tissue damage from highvelocity gunshot injuries can be extensive, and the majority of patients present with major associated injuries and in hemorrhagic shock which necessitates surgical exploration and often results in nephrectomy.

Renal stab wounds are the most common penetrating mechanism for renal injury. Armenakas et al., in their study, demonstrated a successful observation for most of grade I and II renal injuries. However, renal stab wounds producing major renal injuries (grade III) are more unpredictable, and they are associated with a higher rate of delayed complications if treated expectantly.

An emerging aspect of non-operative management is growing experience with angioembolization. Arteriography with selective renal embolization for hemorrhage control is a reasonable alternative to laparotomy provided no other indication for immediate surgery exists. Studies reporting angioembolization in renal trauma report high failure rates of expectant management compared to patients not requiring angioembolization. One of the reasons resulting in this disparity can be secondary to higher injury severity in patients who require angioembolization. Menaker et al., in their study on expectant management of blunt renal injuries, reported higher failure rate in patients undergoing angioembolization [33]. Similarly, Hotaling et al., in their study from national trauma data bank, reported penetrating mechanism as a risk factor for failure of expectant management in patients undergoing angioembolization [34]. Appropriate patient selection is the key for successful non-operative management of 
penetrating renal trauma. Glass et al. recently published their survey on practice of angioembolization by urologist and interventional radiologists (IR) to define current practice patterns. Of the respondents, $73 \%$ supported the use of angioembolization in penetrating trauma, the IR reporting higher use compared to urologists. Similarly, 86 and $66 \%$ of the respondents supported the use of angioembolization for grade IV and V renal injuries, respectively [35]. While vascular injuries can be addressed with interventional radiology, the other aspect to keep in mind is the amount and kind of renal tissue injury. Depending on the site of injury, urine leak may be difficult to handle and it does not cease like blood vessel injuries. These injuries can be managed with drains at a later time, but if the patient is being explored and peripheral renal injuries are identified, drainage at the initial surgery is recommended.

Conclusion Renal trauma has evolved significantly over the past few years. Advancements in diagnostic tools and evolution of injury grading have paved the way for selective nonoperative management. In hemodynamic patients whom renal trauma is suspected, radiographic imaging provides vital information and road map therapy. For peripheral renal injuries identified during surgery, it is recommended that the injury not be explored but merely drained as exploration results in unnecessary nephrectomy. During surgery, if the kidney is explored and injury is identified, then repair and salvage is preferred if the patient can tolerate the time to repair the injury.

\section{Penetrating Splenic Trauma}

The spleen is among the most commonly injured intraabdominal organs. Blunt injury is more common than penetrating splenic trauma. Gunshot and shotgun injuries are more common mechanisms for penetrating spleen trauma compared to stabbings, as the spleen's anatomical location protects it from stab wounds $[36 \bullet, 37 \bullet \bullet]$. A significant portion of penetrating injuries to the spleen results from intraoperative iatrogenic traumatic injuries $[38,39]$. These injuries to the spleen can result from surgical or endoscopic manipulation of the colon, stomach, pancreas, and kidney or with exposure and reconstruction of the proximal abdominal aorta. The risk is greatest when patients undergo colon resection, with $1 \%$ of all colonic resections resulting in penetrating injuries to spleen [40].

The primary goal of any suspected splenic trauma is prompt diagnosis and management of potentially lifethreatening hemorrhage. Preserving functional splenic tissue is secondary and in selected patients may be accomplished by using non-operative management or operative salvage techniques. Emergent splenectomy still remains a life-saving procedure for many patients and the avoidance of splenectomy is not the goal. However, advancements in angiographic techniques and evolution of non-operative management in a select group of patients have changed the focus from the conventional knee jerk reaction splenectomy to consideration for non-operative management.

Diagnosis The most important and critical factor deciding the initial course of management in splenic trauma is the need for emergent surgical exploration. In any patient with signs of hemodynamic instability and evidence of peritonitis or evisceration, surgical exploration is mandatory. The initial history and physical exam should illicit the location and trajectory of impalement. It is also important to define the mental status and reliability of exam to determine if local wound exploration or serial abdominal exams are warranted. In patients who are hemodynamically stable at presentation, further diagnostic workup should be ensued, which can guide the management route of these patients.

a) Focused Assessment with sonography for trauma (FAST): FAST is now the standard of care and is used to initially evaluate for blood in the abdomen and can even visualize splenic injury. However, FAST does not rule out intraabdominal injury. The utility of FAST is also user dependent and affects its sensitivity for ruling out intraabdominal injuries. Penetrating splenic trauma is often complicated with associated hollow viscus injuries and diaphragmatic tear, which cannot be detected by the FAST exam [37••, 41].

b) Computed tomography (CT) scan: The multi-detector CT scanner is the gold standard for detecting splenic injury even in penetrating trauma if the patient does not have immediate indications for laparotomy. IV contrast is often used in these patients to better visualize solid organs, and extravasation of contrast can define the extent of active bleeding. In stable patients with suspected spleen injury, this study can be completed expeditiously and can provide valuable information regarding the non-operative management or potential use of angioembolization. Furthermore, it helps define the AAST injury grade. This grading is a good measure of organ damage and guides the management.

Due to advances in CT imaging, selective nonoperative management of penetrating splenic trauma is gaining favor. It is helpful in elucidating the missile path, delineating organ injury, and identifying patients with injuries amenable to non-operative management (e.g., lowgrade injuries). CT scan findings that indicate splenic injury include hemoperitoneum, hypo-density, contrast blush, or contrast extravasation. The trajectory of the missile also provides information on the likelihood of other associated injuries. 
c) Diagnostic laparoscopy: One of the major concerns with non-operative management of penetrating trauma is fear of missing concomitant injuries. With penetrating trauma to the spleen, concern remains for diaphragmatic tears and hollow viscus injuries, for which CT is not sensitive [42, 43]. Laparoscopic evaluation of left upper quadrant with suspicion of penetrating trauma to the spleen can define the associated diaphragmatic injuries and rule out hemoperitoneum and hollow viscus injuries [44]. Ortega et al., in a case series of 24 patients, reported $100 \%$ positive predictive value and specificity of diagnostic laparoscopy for detecting diaphragmatic, splenic, liver, and hollow viscus injuries [45]. Similarly, Friese et al. reported $100 \%$ specificity, $87.5 \%$ sensitivity, and $96.8 \%$ negative predictive value of diagnostic laparoscopy to rule out diaphragm injury in thoracoabdominal stab wounds [46]. In hemodynamically stable patients with strong suspicion of associated injuries or equivocal findings on a CT scan, diagnostic laparoscopy can provide a valuable assessment of intra-abdominal injuries. Diagnostic laparoscopy can also be useful in hemodynamically stable patients with findings of large amount of hemoperitoneum in the abdomen, where evacuation of the blood can be carried out along with better assessment of the injury.

Splenic Injury Grading The AAST has published a grading scale on spleen injury, which is based on the anatomic injury identified on CT scan (Table 2 [47]). The grade of injury and the degree of hemoperitoneum on CT scan correlate to the success of non-operative management but do not consistently predict the need for initial operative intervention.

Management of Penetrating Splenic Trauma Early in the twentieth century, splenectomy became the standard of care for any splenic injury. Operative mortality of the procedure was low, and the bleeding was effectively stopped and concomitant injuries repaired. This approach was also driven by common dogmas that the spleen had no purpose, splenectomy had no consequences, the spleen cannot heal, and any injured spleen would ultimately bleed with the demise of the patient [8]. In the mid-twentieth century, reports of overwhelming post-splenectomy infections led to the evolution of splenic preservation and ultimately selective non-operative management.

Splenic injury can be managed first with observation, angiographic embolization, or surgery. The decision depends on the patient's hemodynamic status, the grade of splenic injury, and the presence of other injuries and medical comorbidities. Depending on the availability of resources, the management approach used may vary from institution to institution.

a) Operative management: The decision to perform either splenectomy or splenic salvage is made based on the severity of injury, presence and nature of associated injuries, experience of the surgeon, and patient factors.

Splenectomy is a life-saving procedure in patients with hemodynamic compromise secondary to bleeding spleen. Splenectomy may also be considered even for low-grade penetrating splenic injuries, if other abdominal organs are involved and the patient is in hemodynamic compromise. It may also be the best option in situations where institutional resources cannot support non-operative management of splenic injury.

With the advent of non-operative management of lowgrade injuries, splenic salvage is increasingly becoming uncommon. When considering splenic salvage, it should be determined if the patient can tolerate reoperation in case of recurrent hemorrhage [48]. In multi-trauma patients or patients with significant baseline comorbidities, splenectomy appears to be a more appropriate choice as they cannot afford any subsequent episode of hypotension or a reoperation.

In modern times with increasing focus on nonoperative management of splenic injuries, the role of splenic salvage can only be defined in a select group of patients. One such scenario would be a patient undergoing trauma laparotomy, stabilized during surgery, has splenic

Table 2 AAST splenic injury grading

\begin{tabular}{lll}
\hline Grade & Type of injury & Description \\
\hline I & Hematoma & Sub-capsular, $<10 \%$ of surface area \\
& Laceration & Capsular tear, $<1 \mathrm{~cm}$ parenchymal depth \\
II & Hematoma & Sub-capsular: 10 to $50 \%$ of surface area; intraparenchymal: $<5 \mathrm{~cm}$ diameter \\
& Laceration & Capsular tear, $1-$ to 3 -cm parenchymal depth, does not involve a trabecular vessel \\
III & Hematoma & Sub capsular: $>50 \%$ surface area or expanding; ruptured; intraparenchymal $\geq 5 \mathrm{~cm}$ depth \\
& Laceration & $>3 \mathrm{~cm}$ parenchymal depth or involving trabecular vessel \\
IV & Laceration & Involvement of segmental or hilar vessels causing major devascularization $(>25 \%$ of spleen $)$ \\
V & Laceration & Completely shattered spleen \\
& Vascular & Hilar vascular injury which devascularizes spleen \\
\hline
\end{tabular}


bleeding controlled, has non-significant associated injuries, and is not-coagulopathic [49]. If the CT scan on patients with no other indications for surgery, in which a wound tract that does not seem to be bleeding significantly to warrant surgery, does show potential injury to the diaphragm or hollow viscous organs, then the goal of splenic salvage should not prevent the surgeon from laparotomy. In this scenario, drainage of the spleen with or without repair is an option. In some but rare scenarios, the spleen will be injured with a tangential gunshot wound or stab wound and does not seem to warrant laparotomy to repair the diaphragm or hollow viscous injury. In this scenario, the patient should be admitted for serial exams and laparotomy is not immediately required. Of note is that while some may choose to not repair the diaphragm on the right side if it is sufficiently posterior, the standard is to repair diaphragm injuries on the left side.

b) Non-operative management: Before the evolution of the non-operative management, surgery was the exclusive option. In current practice $50-70 \%$ of all splenic injuries are managed non-operatively either by observation alone or observation and angioembolization [50-52].

The role of selective non-operative management of penetrating injuries to the spleen is evolving [53]. The majority of penetrating spleen injuries is hemodynamically unstable and precludes any potential role of nonoperative management. However, patients who are stable at initial presentation without significant splenic injury or contrast extravasation are suitable candidates for trial of non-operative management. Berg et al., in their 11-year experience on penetrating splenic trauma, selected 38 patients for non-operative management. They successfully managed $63 \%$ of these patients. Patients who failed trial of non-operative management were more likely to have hollow viscus and diaphragmatic injuries. Other factors associated with failure of non-operative management include higher-grade splenic injury (>grade III), active contrast extravasation, large volume hemo-peritoneum, traumatic brain injury, or altered neurologic status, which precludes adequate serial examination of the abdomen $[37 \bullet \bullet$.

Observation Successful observation during non-operative management for splenic trauma depends on two factors, proper patient selection and adequate resources within the institution. Patients should be closely monitored by the nursing and medical staff, and there should be sufficient flexibility to allow urgent/emergent intervention if angioembolization or surgery is required.

There is a wide variation in the clinical application of nonoperative strategies, but, generally, patients are admitted to a setting that provides monitored care, either to an intensive care or to a step-down unit. The type of unit depends on the capabilities of the unit, the grade of splenic injury, the nature and severity of other injuries, and the patient's clinical status [54•]. Serial hemoglobin monitoring should be done every $6 \mathrm{~h}$ during the first $24 \mathrm{~h}$ or until the hemoglobin level becomes stable.

For patients being observed, a second repeat $\mathrm{CT}$ imaging is necessary depending on the injury and requires clinical judgment. The duration of observation should be individualized based on the grade of splenic injury, the nature and severity of other injuries, and the patient's clinical status. One multicenter trial on blunt splenic trauma found that $86 \%$ of patients who failed non-operative management did so within $96 \mathrm{~h}$ of hospital admission; $61 \%$ of failures occurred during the first $24 \mathrm{~h}$ [55]. Patients with higher-grade injuries may require longer periods of observation.

Patients who fail observation will require either splenic embolization or, more commonly, operative management. Patients who fail observational management may be inpatients or, more rarely, outpatients presenting with "delayed splenic rupture." It is likely that "delayed rupture" more accurately describes those patients with splenic parenchymal pseudoaneurysms. The walls of these pseudoaneurysms degrade during the normal process of clot dissolution with delayed bleeding.

When observing patients with splenic injury, there is no consensus about level of hemoglobin, change in hemoglobin, or transfusion volume that indicates a need for intervention. Some surgeons intervene before the need for a transfusion as a way to avoid allogeneic exposure. Others will make provisions for several units of PRBC before further intervention.

The choice to pursue embolization or surgery is governed in many institutions by the availability of appropriate resources and the ability of the patient to tolerate the time needed to set up an interventional radiology suite (or operating room with dedicated arteriography), get staff in place, and perform the embolization procedure. Depending on the patient's anatomy, this can be a lengthy procedure.

Splenic Embolization Angiographic embolization was first applied to the management of splenic injury in 1981. Splenic embolization requires specialized imaging facilities and a vascular interventionalist (for example, an interventional radiologist or vascular surgeon) who is experienced with celiac artery catheterization and embolization techniques. Embolization, where available, is potentially most useful when used selectively in hemodynamically stable patients who have CT findings that include active contrast extravasation, splenic pseudoaneurysm, or large-volume hemoperitoneum.

The experience of angioembolization in penetrating splenic trauma derives widely from success in blunt splenic injuries. Several authors have reported their successes with angioembolization in hemodynamically stable patients with penetrating spleen injuries [56-58]. However, the literature 
is lacking on appropriate patient selection and outcomes of angioembolization in penetrating spleen injuries. Perhaps patients who are hemodynamically stable and show an evidence of contrast extravasation on initial CT scan are appropriate candidates for angioembolization.

Conclusion Penetrating injuries to the spleen provide a unique management challenge. With the evolution of nonoperative management, appropriate patient selection is mandatory. Optimal use of enhanced imaging modalities and less invasive interventional tools can improve the organ salvage rates; however, hemorrhage control still carries the precedence. There are infrequent cases of tangential gunshot wounds with minor injuries without major bleeding that can be managed non-operatively if the trajectory of the bullet does not indicate associated injuries including the diaphragm. In certain cases, a stab wound to the spleen under the ribs can result in isolated splenic injuries and these are ideal candidates for non-operative management if the spleen is not actively bleeding. If the diaphragm is seemingly injured with associated hemo/pneumothorax or the trajectory seems to involve the spleen, a laparoscopy should be done at the minimum.

\section{Compliance with Ethics Guidelines}

Conflict of Interest Bellal Joseph, Mazhar Khalil, and Peter Rhee declare no conflicts of interest.

Human and Animal Rights and Informed Consent This article does not contain any studies with human or animal subjects performed by any of the authors.

\section{References}

Papers of particular interest, published recently, have been highlighted as:

- Of importance

•• Of major importance

1. Como JJ, Bokhari F, Chiu WC, et al. Practice management guidelines for selective nonoperative management of penetrating abdominal trauma. J Trauma. 2010;68(3):721-33.

2. Renz BM, Feliciano DV. Unnecessary laparotomies for trauma: a prospective study of morbidity. J Trauma. 1995;38(3):350-6.

3. Friedmann P. Selective management of stab wounds of the abdomen. Arch Surg. 1968;96(2):292-5.

4. Fikry K, Velmahos GC, Bramos A, et al. Successful selective nonoperative management of abdominal gunshot wounds despite low penetrating trauma volumes. Arch Surg. 2011;146(5):528-32.

5. Beekley AC, Blackbourne LH, Sebesta JA, McMullin N, Mullenix PS, Holcomb JB. Selective nonoperative management of penetrating torso injury from combat fragmentation wounds. J Trauma. 2008;64(2):S108-16. discussion S116-107.

6. Zafar SN, Rushing A, Haut ER, et al. Outcome of selective nonoperative management of penetrating abdominal injuries from the
North American National Trauma Database. Br J Surg. 2012;99(1): 155-64. The paper provides practice trends and outcomes of selective non-operative management in penetrating abdominal trauma using National Trauma Data Bank.

7. Demetriades D, Hadjizacharia P, Constantinou C, et al. Selective nonoperative management of penetrating abdominal solid organ injuries. Ann Surg. 2006;244(4):620-8.

8. Peitzman AB, Richardson JD. Surgical treatment of injuries to the solid abdominal organs: a 50-year perspective from the Journal of Trauma. J Trauma. 2010;69(5):1011-21.

9. Wessells H, Suh D, Porter JR, et al. Renal injury and operative management in the United States: results of a population-based study. J Trauma. 2003;54(3):423-30.

10. Santucci RA, Wessells H, Bartsch G, et al. Evaluation and management of renal injuries: consensus statement of the renal trauma subcommittee. BJU Int. 2004;93(7):937-54.

11. Kansas BT, Eddy MJ, Mydlo JH, Uzzo RG. Incidence and management of penetrating renal trauma in patients with multiorgan injury: extended experience at an inner city trauma center. J Urol. 2004; 172(4 Pt 1):1355-60.

12. Armenakas NA, Duckett CP, McAninch JW. Indications for nonoperative management of renal stab wounds. J Urol. 1999;161(3): 768-71.

13. Nicol AJ, Theunissen D. Renal salvage in penetrating kidney injuries: a prospective analysis. J Trauma. 2002;53(2):351-3.

14. Carroll PR, McAninch JW, Klosterman P, Greenblatt M. Renovascular trauma: risk assessment, surgical management, and outcome. J Trauma. 1990;30(5):547-52. discussion 553-544.

15. Palmer LS, Rosenbaum RR, Gershbaum MD, Kreutzer ER. Penetrating ureteral trauma at an urban trauma center: 10-year experience. Urology. 1999;54(1):34-6.

16. Wilson RF, Ziegler DW. Diagnostic and treatment problems in renal injuries. Am Surg. 1987;53(7):399-402.

17. Federle MP, Brown TR, McAninch JW. Penetrating renal trauma: CT evaluation. J Comput Assist Tomogr. 1987;11(6):1026-30.

18. McGahan JP, Richards JR, Jones CD, Gerscovich EO. Use of ultrasonography in the patient with acute renal trauma. J Ultrasound Med. 1999;18(3):207-13. quiz 215-206.

19. Bretan Jr PN, McAninch JW, Federle MP, Jeffrey Jr RB. Computerized tomographic staging of renal trauma: 85 consecutive cases. J Urol. 1986;136(3):561-5.

20. Morey AF, McAninch J, Tiller BK, Duckett C, Carroll PR. Single shot intraoperative excretory urography for the immediate evaluation of renal trauma. J Urol. 1999;161(4):1088-92.

21. Qin R, Wang P, Qin W, Wang H, Chen B. Diagnosis and treatment of renal trauma in 298 patients. Chin J Traumatol. 2002;5(1):21-3.

22. Halsell RD, Vines FS, Shatney CH, et al. The reliability of excretory urography as a screening examination for blunt renal trauma. Ann Emerg Med. 1987;16(11):1236-9.

23. Cass A, Vieira J. Comparison of IVP and CT findings in patients with suspected severe renal injury. Urology. 1987;29(5):484-7.

24. Marcos HB, Noone TC, Semelka RC. MRI evaluation of acute renal trauma. J Magn Reson Imaging. 1998;8(4):989-90.

25. $\mathrm{Ku} J H$, Jeon YS, Kim ME, Lee NK, Park YH. Is there a role for magnetic resonance imaging in renal trauma? Int J Urol. 2001;8(6): 261-7.

26. Leppäniemi A, Lamminen A, Tervahartiala P, Salo J, Haapiainen R, Lehtonen T. MRI and CT in blunt renal trauma: an update. Paper presented at: Seminars in Ultrasound, CT and MRI1997.

27. Buckley JC, McAninch JW. Revision of current American Association for the Surgery of Trauma Renal Injury grading system. J Trauma. 2011;70(1):35-7.

28. Santucci RA, McAninch JW, Safir M, Mario LA, Segal MR. Validation of the American Association for the Surgery of Trauma organ injury severity scale for the kidney. J TraumaInjury Infection Critical Care. 2001;50(2):195-200. 
29. McAninch JW, Carroll PR, Klosterman PW, Dixon CM, Greenblatt MN. Renal reconstruction after injury. J Urol. 1991;145(5):932-7.

30. Thall EH, Stone NN, Cheng DL, et al. Conservative management of penetrating and blunt type III renal injuries. Br J Urol. 1996;77(4): $512-7$.

31. Velmahos GC, Demetriades D, Cornwell 3rd EE, et al. Selective management of renal gunshot wounds. Br J Surg. 1998;85(8): $1121-4$.

32. Navsaria PH, Nicol AJ. Selective nonoperative management of kidney gunshot injuries. World J Surg. 2009;33(3):553-7.

33. Menaker J, Joseph B, Stein DM, Scalea TM. Angiointervention: high rates of failure following blunt renal injuries. World J Surg. 2011;35(3):520-7.

34. Hotaling JM, Sorensen MD, Smith 3rd TG, Rivara FP, Wessells H, Voelzke BB. Analysis of diagnostic angiography and angioembolization in the acute management of renal trauma using a national data set. J Urol. 2011;185(4):1316-20.

35. Glass AS, Appa AA, Kenfield SA, et al. Selective angioembolization for traumatic renal injuries: a survey on clinician practice. World J Urol. 2014;32(3):821-7.

36. Berg RJ, Karamanos E, Inaba K, Okoye O, Teixeira PG, Demetriades D. The persistent diagnostic challenge of thoracoabdominal stab wounds. J Trauma Acute Care Surg. 2014;76(2):418-23. The research is about a single-center experience on the diagnostic approaches for thoracoabdominal stab wounds.

37.• Berg RJ, Inaba K, Okoye O, et al. The contemporary management of penetrating splenic injury. Injury. 2014;45(9):1394-400. The research is a single-center experience identifying potential candidates for non-operative management after penetrating splenic trauma.

38. Tan K, Lewis GR, Chahal R, et al. Iatrogenic splenectomy during left nephrectomy: a single-institution experience of eight years. Urol Int. 2011;87(1):59-63.

39. Cassar K, Munro A. Iatrogenic splenic injury. J R Coll Surg Edinb. 2002;47(6):731-41.

40. Masoomi H, Carmichael JC, Mills S, Ketana N, Dolich MO, Stamos MJ. Predictive factors of splenic injury in colorectal surgery: data from the Nationwide Inpatient Sample, 2006-2008. Arch Surg. 2012;147(4):324-9.

41. Natarajan B, Gupta PK, Cemaj S, Sorensen M, Hatzoudis GI, Forse RA. FAST scan: is it worth doing in hemodynamically stable blunt trauma patients? Surgery. 2010;148(4):695-700. discussion 700691.

42. Stuhlfaut JW, Soto JA, Lucey BC, et al. Blunt abdominal trauma: performance of CT without oral contrast material. Radiology. 2004;233(3):689-94.

43. Hammer MM, Flagg E, Mellnick VM, Cummings KW, Bhalla S, Raptis CA. Computed tomography of blunt and penetrating diaphragmatic injury: sensitivity and inter-observer agreement of CT signs. Emerg Radiol. 2014;21(2):143-9.

44. Joseph DK, Kunac A, Kinler RL, Staff I, Butler KL. Diagnosing blunt hollow viscus injury: is computed tomography the answer? Am J Surg. 2013;205(4):414-8.

45. Ortega AE, Tang E, Froes ET, Asensio JA, Katkhouda N, Demetriades D. Laparoscopic evaluation of penetrating thoracoabdominal traumatic injuries. Surg Endosc. 1996;10(1): $19-22$.

46. Friese RS, Coln CE, Gentilello LM. Laparoscopy is sufficient to exclude occult diaphragm injury after penetrating abdominal trauma. J Trauma. 2005;58(4):789-92.

47. Tinkoff G, Esposito TJ, Reed J, et al. American Association for the Surgery of Trauma Organ Injury Scale I: spleen, liver, and kidney, validation based on the National Trauma Data Bank. J Am Coll Surg. 2008;207(5):646-55.

48. Franklin GA, Casos SR. Current advances in the surgical approach to abdominal trauma. Injury. 2006;37(12):1143-56.

49. Mitsusada M, Nakajima Y. Protocol for splenic salvage procedures in this era of non-operative management. Acute Med Surg. 2014.

50. McIntyre LK, Schiff M, Jurkovich GJ. Failure of nonoperative management of splenic injuries: causes and consequences. Arch Surg. 2005;140(6):563-8. discussion 568-569.

51. Bhullar IS, Frykberg ER, Siragusa D, et al. Selective angiographic embolization of blunt splenic traumatic injuries in adults decreases failure rate of nonoperative management. J Trauma Acute Care Surg. 2012;72(5):1127-34.

52. Stein DM, Scalea TM. Nonoperative management of spleen and liver injuries. J Intensive Care Med. 2006;21(5):296-304.

53. Pachter H, Guth A, Hofstetter S, Spencer F. Changing patterns in the management of splenic trauma: the impact of nonoperative management. Ann Surg. 1998;227(5):708.

54. Gomez D, Haas B, Al-Ali K, Monneuse O, Nathens AB, Ahmed N. Controversies in the management of splenic trauma. Injury. 2012;43(1):55-61. The paper is a survey of trauma surgeons on the controversies in the management of splenic trauma.

55. Peitzman AB, Heil B, Rivera L, et al. Blunt splenic injury in adults: Multi-institutional Study of the Eastern Association for the Surgery of Trauma. J Trauma. 2000;49(2):177-87. discussion 187-179.

56. Velmahos GC, Demetriades D, Chahwan S, et al. Angiographic embolization for arrest of bleeding after penetrating trauma to the abdomen. Am J Surg. 1999;178(5):367-73.

57. Velmahos GC, Chahwan S, Falabella A, Hanks SE, Demetriades D. Angiographic embolization for intraperitoneal and retroperitoneal injuries. World J Surg. 2000;24(5):539-45.

58. Rosati C, Ata A, Siskin GP, Megna D, Bonville DJ, Stain SC. Management of splenic trauma: a single institution's 8-year experience. Am J Surg. 2014. 